\title{
Language barriers to informed consent for dermatologic interventions.
}

Jordan Wang

Thomas Jefferson University

Matthew Keller

Director Psoriasis Center SKMC

Follow this and additional works at: https://jdc.jefferson.edu/dcbfp

Part of the Dermatology Commons

Let us know how access to this document benefits you

\section{Recommended Citation}

Wang, Jordan and Keller, Matthew, "Language barriers to informed consent for dermatologic interventions." (2014). Department of Dermatology and Cutaneous Biology Faculty Papers. Paper 51.

https://jdc.jefferson.edu/dcbfp/51

This Article is brought to you for free and open access by the Jefferson Digital Commons. The Jefferson Digital Commons is a service of Thomas Jefferson University's Center for Teaching and Learning (CTL). The Commons is a showcase for Jefferson books and journals, peer-reviewed scholarly publications, unique historical collections from the University archives, and teaching tools. The Jefferson Digital Commons allows researchers and interested readers anywhere in the world to learn about and keep up to date with Jefferson scholarship. This article has been accepted for inclusion in Department of Dermatology and Cutaneous Biology Faculty Papers by an authorized administrator of the Jefferson Digital Commons. For more information, please contact: JeffersonDigitalCommons@jefferson.edu. 


\title{
Dermatoethics CONSUltation
}

\section{Language barriers to informed consent for dermatologic interventions}

\author{
Jordan Wang, MBE, and Matthew Keller, MD \\ Philadelphia, Pennsylvania
}

\begin{abstract}
A n ethical dilemma may present itself when dermatologists must obtain informed consent from patients with limited English-language proficiency. With an increasingly diverse populatio$\mathrm{n}$-both culturally and linguistically-and the significant role that biopsies play in our field, it is crucial that dermatologists learn how to navigate this ethical quandary through recognizing the importance of using trained medical interpreters rather than untrained, biased, and/or minor individuals, eg, most
\end{abstract}

family members or office staff members. Although some may consider this to be purely a legal issue, the law, in addition to the American Medical Association and the Canadian Medical Association codes of ethics, is extremely vague and imprecise, which subsequently produces a gray area in which physicians can operate. Dermatologists must recognize that they have professional, legal, and moral obligations to respect patient autonomy by properly obtaining informed consent before any medical intervention.

\section{CASE SCENARIO}

A 39-year-old Spanish-speaking woman with limited English-language proficiency presents with her 13-year-old son to your private dermatology practice. Through her son, you learn the patient is worried about a mole that has significantly grown in size over the past 3 months. After examination, you recommend the nevus be biopsied to better evaluate it. However, you are barely able to communicate with the patient, and you suspect that her son is not interpreting everything you say based on his especially brief communications with her. To proceed with the biopsy, you must first obtain informed consent.

\section{As the dermatologist, you should:}

A. Do your best to convey the medical information yourself to obtain informed consent.

B. Allow her son to interpret the medical information so that you can obtain informed consent.

C. Use an office staff member who speaks some Spanish to help you obtain informed consent.

D. Call the language line and use a trained medical interpreter to help you obtain informed consent.

\section{DISCUSSION}

Although some may see this purely as a legal issue, several potential ethical conflicts exist. These include the attempts by many physicians to discourage patients with limited English-language proficiency from receiving care and also physician misinterpretation because of lack of education or cultural understanding. Many dermatologists would

From the Department of Dermatology and Cutaneous Biology, Thomas Jefferson University.

Funding sources: None.

Conflicts of interest: None declared.

Correspondence to: Matthew Keller, MD, Department of Dermatology and Cutaneous Biology, Thomas Jefferson prefer not to see such patients because of the anticipated burden. As a quick solution, private dermatologists often refer these patients to academic centers under the pretense of needing an expert, when they are actually sending these patients away to avoid the time and expense involved. This allows them to continue to see high volumes of patients in their own practice. To prevent such occurrences,

University Hospital, 833 Chestnut St, Suite 740, Philadelphia,

PA 19107. E-mail: matthew.keller@jefferson.edu.

J Am Acad Dermatol 2014;70:366-8.

0190-9622/\$36.00

(C) 2013 by the American Academy of Dermatology, Inc.

http://dx.doi.org/10.1016/j.jaad.2013.08.043 
dermatologists must be able to acknowledge their obligations to the patient and recognize the best strategies for delivering ethical and culturally competent care.

Physicians have professional, legal, and moral obligations to respect patient autonomy by properly obtaining informed consent before any medical intervention. Patients with decision-making capacity should be given sufficient information regarding the risks, benefits, and alternatives of any planned treatment or procedure to allow them to make a voluntary informed decision. In the above scenario, the dermatologist has a duty to inform the patient of such information pertaining to the proposed biopsy in a language that she can comprehend. Furthermore, the patient must have the opportunity to ask questions to the dermatologist in a language that the latter can comprehend. Assuming that there is no common language in this scenario, a significant burden is placed on the interpreting party to accurately convey the communications between the dermatologist and the patient in a manner that each can comprehend. Depending on the sensitive nature of some of this information, the patient may not be comfortable using either a relative or a friend to help interpret the encounter.

Although the above scenario references a patient with limited English-language proficiency, the same ethical principles apply to patients with hearing impairments. For these patients, the dermatologist is obligated to make a sign-language interpreter available to the patient during encounters where either significant or large amounts of information must be exchanged. During encounters that involve the communication of very little information, such as refilling prescriptions, lip reading and written notes may be all that is needed to ensure effective patient-physician communication.

Given the diverse nature of the North American population, such scenarios as the one above are becoming an everyday occurrence in medical practice. Despite the initiatives of all medical schools to teach culturally competent care, only $20 \%$ of recent graduates felt prepared to treat patients with limited English-language proficiency. ${ }^{1}$ However, training students to work with medical interpreters improved their preparedness. The study by Rodriguez et $\mathrm{al}^{1}$ serves to underscore the importance of professional medical interpreters in meeting the needs of a culturally and linguistically diverse patient population.

Trained interpreters are often able to sense when the patient's understanding of disease is colored by local superstition, cultural belief systems, or religion. This can be helpful when patients believe that their illness can only be explained by a particular cultural phenomenon. In such cases, the professional interpreter is responsible for explaining the reasoning to the physician. Furthermore, interpreters possess the medical vocabulary in other languages necessary for a clear translation, whereas untrained individuals and minors may not have this expertise. Medical interpreters are also trained to be completely impartial. In contrast, family members may have personal motivations, priorities, or biases that conflict with what truly serves the best interests of the patient. Results from a systematic review suggest that the satisfaction, quality of care, and outcomes of patients with limited Englishlanguage proficiency are each improved when trained medical interpreters are used. ${ }^{2}$ For all of these reasons, a trained medical interpreter is vital to the informed consent process in the above scenario.

The legal basis for providing language assistance to patients with limited English-language proficiency comes from Title VI of the Civil Rights Act of 1964, which has been frequently revisited and supported by the Office for Civil Rights of the Department of Health and Human Services. ${ }^{3}$ The delay or denial of medical services because of language barriers is considered to be an act of discrimination. However, the law, in addition to the American Medical Association and the Canadian Medical Association codes of ethics, neither explicitly states which language assistance services must be provided nor mandates the use of interpreters in all situations. ${ }^{4,5}$ Because of this, there currently exists a gray area in which to operate that necessitates a thorough legislative re-examination.

As of 2006, 13 states have offered third-party reimbursements for medical interpreter services. ${ }^{6}$ However, other states have frequently cited cost concerns as the main reason for not adopting similar legislation. Despite ongoing implementation, services that provide language assistance to patients are often unavailable or not made available in private practices and small to medium-sized clinics. This may be a result of the cost and burden that these patients are perceived to place on a medical practice. If private insurance companies and the state and federal governments refuse to reimburse these costs, then the financial burden of the unfunded mandate falls squarely but unevenly on the providers, especially in regions with large numbers of non-Englishlanguage speakers. This is an area in which our health care system is seriously flawed and warrants timely reform. 


\section{ANALYSIS OF CASE SCENARIO}

Option (A) is alarming because the dermatologist cannot fully inform the patient about the recommended intervention. If the 2 parties are unable to effectively communicate with each other, then it is highly unlikely that an understanding of the procedure will result from their continued dialogue. Although this option may seem attractive-because of ongoing time constraints in the clinic and the general opinion that biopsies are relatively low risk-the violation to patient autonomy is too great to ignore. Physicians must allow for and respect the informed decisions of their patients.

Option (B) is not recommended, because family members cannot always be trusted to act as faithful medical interpreters. Such individuals may possess personal agendas or interject unsolicited opinions into the decision-making process, and outside influences may conflict with the best interests of the patient. Entrusting a family member with absolute control over patientphysician communications may not be ideal. Further complicating matters, the above scenario involves the patient's 13-year-old son. It is presumed in our society that minors lack the capacity to provide informed consent for a given intervention by virtue of their age and inherent lack of maturity. For similar reasons, physicians should avoid recruiting minors as interpreters, where they are put in a position to actively influence the consent of another for that very same intervention.

Option (C) is not the best solution because it assumes the staff member is proficient enough in Spanish to act as a competent medical interpreter. This individual may also lack the experience and training that is essential to interpreting medical vocabulary in Spanish. The dermatologist is unable to guarantee that the staff member can accurately convey the intended message to the patient and vice versa. In clinical settings where neither language lines nor trained medical interpreters are available, this may present as the best option dependent upon the staff member's level of fluency. We recommend that bilingual staff members enroll in certification courses to master medical vocabulary in their respected languages.

Option (D) acknowledges the importance of a proper informed consent process and recognizes the specific skill set intrinsic to trained medical interpreters. With this option, the dermatologist respects the patient's autonomy by allowing for an informed decision that is free of external influences. Because trained medical interpreters may not always be accessible, especially in private or rural clinics, physicians should exercise their best judgment when recruiting a family member or an untrained staff member to interpret the patient encounter, and if available, use a remote language line.

\section{BOTTOM LINE}

Patients with limited English-language proficiency are consuming increasingly more health care. When such patients require medical intervention, physicians must respect the informed consent process to deliver culturally competent care. Using trained medical interpreters is the single most effective technique for ensuring that these patients make voluntary informed decisions. This is not a purely legal issue. Contemporary bioethics rests on the central principle of autonomy, and autonomy requires that the patient be as fully informed as possible. A lack of funding for interpreter services does not lessen the physician's ethical obligations to the patient. The reader need only imagine facing surgery in a health care facility abroad, where Urdu is the only language spoken by the providers, to grasp the importance of this obligation and its impact on the patient.

\section{REFERENCES}

1. Rodriguez F, Cohen A, Betancourt JR, Green AR. Evaluation of medical student self-rated preparedness to care for limited English proficiency patients. BMC Med Educ 2011; 11:26.

2. Flores G. The impact of medical interpreter services on the quality of health care: a systematic review. Med Care Res Rev 2005;62:255-99.

3. Chen $A H$, Youdelman MK, Brooks J. The legal framework for language access in healthcare settings: title $\mathrm{VI}$ and beyond. J Gen Intern Med 2007;22(Suppl):362-7.

4. American Medical Association Code of Medical Ethics. Opinion 9.121-racial and ethnic health care disparities, 2005. Available from: URL:http://www.ama-assn.org/ama/ pub/physician-resources/medical-ethics/code-medical-ethics/ opinion9121.page. Accessed August 12, 2013.

5. Canadian Medical Association. CMA code of ethics, 2004. Available from: URL: http://policybase.cma.ca/dbtw-wpd/ PolicyPDF/PD04-06.pdf. Accessed August 12, 2013.

6. Flores G. Language barriers to health care in the United States. N Engl J Med 2006;355:229-31. 